\title{
Mechanisms behind the Synergistic Effect of Sirolimus and Imatinib in Preventing Restenosis after Intimal Injury
}

\author{
Nina-Maria Tigerstedt Einari Aavik Satu Lehti Pekka Hayry \\ Hanna Savolainen-Peltonen \\ Transplantation Laboratory, University of Helsinki and Helsinki University Central Hospital, Helsinki, Finland
}

\section{Key Words}

Sirolimus · Imatinib mesylate $\cdot$ Intimal hyperplasia $\cdot$

Restenosis $\cdot$ Smooth muscle cells

\begin{abstract}
Background: We have shown that the combination of sirolimus and imatinib synergistically inhibits denudation-induced neointimal hyperplasia in rats. We have now dissected the mechanisms behind this synergy and evaluated its long-term efficacy. Methods: After aortic denudation injury, rats received established submaximal doses of sirolimus (1.0 $\mathrm{mg} / \mathrm{kg} /$ day), imatinib $(10.0 \mathrm{mg} / \mathrm{kg} /$ day), the combination of these, or vehicle per os from 3 days before the operation until 14 days after injury. Vessel histology and complete blood counts were monitored until 90 days after injury. Neointimal cell outgrowth, migration and proliferation were evaluated in ex vivo vessel cultures. Quantitative real-time polymerase chain reaction and immunohistochemistry were used for gene and protein expression analysis. Results: The combination therapy caused a synergistic decrease in the number of neointimal nuclei and area throughout the observation period. It also prevented postinjury thrombocytosis and leukocytosis, and almost abolished neointimal cell outgrowth and migration. Furthermore, the combination therapy resulted in upregulation of smooth muscle cell (SMC) markers SM $22 \alpha$ and cysteine and glycine-rich protein 2, and of the antiapoptotic BCL2 mRNA. Conclusions: Combination therapy confers superior long-term vasculoprotection, possibly by
\end{abstract}

inhibition of postoperative thrombocytosis and leukocytosis, inhibition of neointimal cell migration to the injury site and maintenance of cell integrity by inhibition of apoptosis and SMC dedifferentiation. Copyright $\odot 2008$ s. Karger AG, Basel

\section{Introduction}

The success of angioplasty and endovascular surgery is severely limited by fibroproliferative restenosis. The introduction of stents coated with the mTOR inhibitor sirolimus has dramatically reduced restenosis rates after percutaneous coronary revascularization [1]. However, recent reports indicate a higher incidence of late stent thrombosis and hypersensitivity reactions and a possible higher rate of death associated with sirolimus-eluting stents (SESs) compared to bare metal stents [2,3]. After SES implantation, lifelong antiplatelet treatment might be required, entailing risks and patient compliance issues [2]. Furthermore, the currently considered safe use of SESs is also limited to very specific vessel and lesion types [4]. Prevention of restenosis with oral sirolimus has been successful after angioplasty in animal models [5] and after implantation of bare metal stents in clinical trials $[6$, 7], but in patients, the treatment has been limited by side effects related to the high drug doses needed for inhibition of restenosis [8].

\section{KARGER}

Fax +4161306 1234 E-Mail karger@karger.ch www.karger.com
(C) 2008 S. Karger AG, Basel $1018-1172 / 09 / 0463-0240 \$ 26.00 / 0$

Accessible online at:

www.karger.com/jvr
Dr. Nina-Maria Tigerstedt

Transplantation Laboratory, University of Helsinki

Haartmaninkatu 3, PO Box 21

FI-00014 Helsinki (Finland)

Tel. +358 9 1911, Fax +3589241 1227, E-Mail nina-maria.tigerstedt@helsinki.fi 
Imatinib mesylate is an inhibitor of the platelet-derived growth factor (PDGF) receptor kinase, bcr-abl kinase, and c-Kit receptor kinase [9] and is in clinical use for the treatment of several cancer types. In animal models, imatinib has shown vasculoprotective properties; it has been reported to inhibit denudation-injury-induced neointimal hyperplasia $[10,11]$, transplant arteriopathy [12] and diabetes-associated atherosclerosis [13].

We have recently reported a synergistic effect between sirolimus and imatinib in the prevention of restenosis after balloon injury in rats, lasting up to 40 days after injury [14]. The synergy was seen already at well-tolerated submaximal doses of the drugs. This suggests a potential for this oral combination therapy as an alternative for the prevention of neointimal hyperplasia after endovascular interventions.

This study was designed to elucidate the long-term efficacy of the combination treatment by extending the follow-up to 90 days and to gain mechanistic insights by investigating how the drugs separately, and in combination, affect the proliferation and migration of neointimal cells and gene expression in the injured rat vascular wall.

\section{Materials and Methods}

\section{Aortic Denudation Injury}

Aortic denudations were performed on male Wistar rats (250$300 \mathrm{~g}, \mathrm{n}=5-7$ per group; Harlan, Horst, The Netherlands) as described [15]. The rats were anesthetized with $240 \mathrm{mg} / \mathrm{kg}$ i.p. chloral hydrate. Buprenorphine (Temgesic, Reckitt Coleman, Hull, UK) was given for postoperative pain relief. All animals received humane care in compliance with the Guide for the Care and Use of Laboratory Animals published by the US National Institutes of Health (NIH Publication No. 85-23, revised 1996). The protocol for this study was approved by the Local Research Ethics Committee of the University of Helsinki and Uusimaa Health District (licence No. STU162A).

\section{Drugs, Treatments and Vessel Histology}

Sirolimus (Rapamune oral solution; Wyeth Europa, Berkshire, UK) and imatinib (Glivec capsules; Novartis, Basel, Switzerland) were administered orally once a day via a curved gavage needle. Sirolimus was stored in the dark at $4^{\circ} \mathrm{C}$ and used as prescribed. Imatinib was dissolved in PBS at a concentration of $10 \mathrm{mg} / \mathrm{ml}$, stored at $4^{\circ} \mathrm{C}$ and used within 3 days.

The rats were treated with previously established submaximal doses of (1) sirolimus $1.0 \mathrm{mg} / \mathrm{kg} / \mathrm{day}$, (2) imatinib $10.0 \mathrm{mg} / \mathrm{kg} / \mathrm{day}$, (3) a combination of these, or (4) vehicle [14]. Treatment was initiated 3 days before the operation and continued until 14 days after the injury. Sirolimus treatment was started, as in the clinic, with an oral loading dose of $3.0 \mathrm{mg} / \mathrm{kg}$. The animals were weighed daily during the treatment period, and thereafter at 40 and 90 days after the injury.
The animals were sacrificed at 4, 14, 40 and 90 days after the injury for evaluation of the treatments. For the quantitative realtime polymerase chain reaction (QRT-PCR), a set of animals was also sacrificed at $0,2,3,5,7,14,30$ and 60 days after injury. The midsection of the vessel was used for histology, and the end parts for RNA isolation. Histological specimens were processed as described [15]. Cell numbers were quantitated microscopically from paraffin cross-sections stained with Mayer's hematoxylin-eosin, using $\times 400$ magnification; the histological picture was digitalized with an Olympus video microscope and quantitated with Windows Image-Pro Plus Ver. 4.1.0.0 software. The measurements included the areas inside the internal elastic lamina and the external elastic lamina, and the lumen perimeter length.

\section{Complete Blood Counts}

Whole blood samples were collected in EDTA tubes at sacrifice at 4, 14, 40 and 90 days after injury for a complete blood count including white blood cell count, white blood cell differential count, red blood cell count, hemoglobin, hematocrit, platelet count, mean corpuscular volume, mean corpuscular hemoglobin and mean corpuscular hemoglobin concentration. Samples from untreated and unoperated rats were collected to obtain normal values. All samples were analyzed at the Central Laboratory of the Department of Clinical Veterinary Sciences at the University of Helsinki with a Cell-Dyn 3700 System hematology analyzer (Abbott Laboratories, Santa Clara, Calif., USA).

\section{Explant Culture}

Aortic explants were obtained and cultured as described [16]. The culture medium consisted of Dulbecco's modified Eagle's medium (Gibco, Paisley, UK) supplemented with 10\% fetal bovine serum (Gibco), $100 \mathrm{IU} / \mathrm{ml}$ penicillin, $100 \mu \mathrm{g} / \mathrm{ml}$ streptomycin and $2 \mathrm{mmol} / \mathrm{l} \mathrm{L}$-glutamine.

The animals were sacrificed at day 2 after injury, $2 \mathrm{~h}$ after drug administration. The aortas, including all layers of the vessel, were opened longitudinally and explants measuring $1 \times 1 \mathrm{~mm}$ were prepared using a Mcllwain tissue chopper (Mickle Laboratory Engineering, Guilford, UK). The explants were placed individually into the wells of a flat-bottomed 96-well plate (Nunc, Roskilde, Denmark) with $200 \mu$ l test medium. The plates were placed in a $37^{\circ} \mathrm{C}$ incubator with an atmosphere of $95 \%$ air and $5 \% \mathrm{CO}_{2}$.

After $48 \mathrm{~h}$ of culture, each well was observed and counted as positive for outgrowth if one or more cells had grown out of the explants. The distance that the leading edge of migrating cells in each well had traveled from the explant was measured using a calibrated graticule (Olympus, Tokyo, Japan). To quantitate proliferating cells, we measured the incorporation of tritiated thymidine $\left(25 \mathrm{Ci} / \mathrm{mmol}^{3} \mathrm{H}-\mathrm{TdR}\right.$; Amersham International, Amersham, $\mathrm{UK})$ in the explant.

\section{Quantitative Real-Time Polymerase Chain Reaction}

Total RNA was extracted from harvested rat arteries using RNeasy Mini spin columns (Qiagen GmbH, Hilden, Germany). The quality of recovered RNA was determined on an Agilent 2100 Bioanalyzer (Agilent, Palo Alto, Calif., USA) and the RNA integrity value was always better than 5 . Pooled rat total RNA samples were amplified according to an established technique [17]. Five micrograms of amplified anti-sense RNA were reverse transcribed in a standard reaction containing $4 \mu \mathrm{g}$ of random hexamers and $1 \mu \mathrm{l}$ of SuperScript II reverse transcriptase (Invitrogen, 
Table 1. Primers used for QRT-PCR

\begin{tabular}{|c|c|c|}
\hline Definition & Sequence $5^{\prime} \rightarrow 3^{\prime}$ & $\begin{array}{l}\text { Acces- } \\
\text { sion No. }\end{array}$ \\
\hline SM22 $\alpha$ sense & TGAGCAAGTTGGTGAACAGC & M83107 \\
\hline SM22 $\alpha$ antisense & ATTGAGCCACCTGTTCCATC & \\
\hline CSRP2 sense & TAATGTGGATGGCCTTACCG & U44948 \\
\hline CSRP2 antisense & GGATGGGCAGGAGAGTGTAG & \\
\hline BCL2 sense & GGTGGAGGAACTCTTCAGGGA & S74122 \\
\hline BCL2 antisense & TTGACGCTCTCCACACACATG & \\
\hline vWF sense & GCAGTCAGTTGGCCTCTACC & U50044 \\
\hline vWF antisense & AGCGGGTGAAATACCTAGCC & \\
\hline
\end{tabular}

Carlsbad, Calif., USA) in a total volume of $20 \mu \mathrm{l}$. Nascent cDNA was diluted to $10 \mathrm{ng} / \mathrm{ml}$ with water.

QRT-PCR analysis was performed on a RotorGene 3000 (Corbett Life Science, Sydney, Australia) apparatus using SYBR Green chemistry. The total sample volume of $10 \mu \mathrm{l}$ consisted of $10 \mathrm{ng}$ of cDNA, $500 \mathrm{nmol} / \mathrm{l}$ of both primers and $5 \mu \mathrm{l} 2 \times$ master mix ( $1 \mathrm{mmol} / \mathrm{l} \mathrm{dNTP,} 5 \mathrm{mmol} / 1 \mathrm{MgCl}_{2}, 1: 10,000$ diluted SYBR Green, $2 \times$ AmpliTaq buffer, 0.05 U/ $\mu$ l AmpliTaq Gold; Applied Biosystems, Foster City, Calif., USA). Primers listed in table 1 were picked from PrimerBank [18]. Standard conditions for QRT-PCR were used for all amplifications - initial denaturation at $95^{\circ} \mathrm{C}$ for $10 \mathrm{~min}$ followed by cycling protocol, annealing at $60^{\circ} \mathrm{C}$ for $30 \mathrm{~s}$, extension at $72^{\circ} \mathrm{C}$ for $30 \mathrm{~s}$ and denaturation at $95^{\circ} \mathrm{C}$ for $15 \mathrm{~s}$. After 40 cycles, the final extension was carried out at $72^{\circ} \mathrm{C}$ for 10 min. Changes in gene expression levels were calculated using RotorGene software (Corbett Life Science) with a comparative quantitation algorithm. Changes in expression levels are expressed as n-fold changes $(\log 2)$.

\section{Immunohistochemistry}

To localize the proteins coding for the genes of interest, we used polyclonal antibodies for CSRP2, cysteine- and glycine-rich protein 2 (chicken, 1:200; AbCam, Cambridge, UK), BCL2 (rabbit, 1:100, RDI-MBCL2abr; Fitzgerald, Concord, Mass., USA), von Willebrand factor (vWF, rabbit, 1:200, A0082; Dako, Glostrup, Denmark) and a monoclonal antibody for SM22 $\alpha$ (mouse, 1:100, 10H12; Novocastra, Newcastle upon Tyne, UK). The stainings were performed using a commercial avidin-peroxidase $\mathrm{ABC}$ method (Vectastain Elite ABC Kit; Vector Laboratories, Burlingame, Calif., USA), according to the manufacturer's instructions. The primary antibody was incubated at room temperature for 60 min. The immunostaining was graded separately from the intima, media and adventitia as follows: $0=$ no visible staining; $1=$ some cells with weak staining; 2 = moderate staining with multifocal expression; 3 = intense staining throughout the vessel compartment.

\section{Statistical Analysis}

The data were evaluated with one-way ANOVA with Bonferroni correction or, in the case of nonparametric comparisons, with the Kruskal-Wallis test with Dunn correction. $\mathrm{p}<0.05$ was considered statistically significant.

\section{Results}

\section{Long-Term Effects of Combination Therapy on the Vascular Wall}

We have previously shown that the combination treatment of sirolimus and imatinib at submaximal doses $(1+$ $10 \mathrm{mg} / \mathrm{kg} /$ day, p.o.) for 14 days is well tolerated and produces synergistic suppression of rat neointimal hyperplasia that persists until day 40 after injury [14]. In the present study, we extended the follow-up period to 90 days to determine the long-term efficacy of this combination therapy. When given individually, only sirolimus showed a moderate vasculoprotective effect throughout the observation period while imatinib lost its effect 14 days after injury. Imatinib or sirolimus administered alone resulted in a 24 and $40 \%$ reduction in the number of intimal nuclei $(\mathrm{p}=\mathrm{NS}$ and $\mathrm{p}=0.004)$, respectively, a 28 and $51 \%$ reduction in intimal area $(\mathrm{p}=\mathrm{NS}$ and $\mathrm{p}=0.0319)$ and 4 and $7 \%$ increase in lumen perimeter length $(\mathrm{p}=\mathrm{NS})$, respectively. However, early combination therapy with sirolimus and imatinib, discontinued at day 14 after injury, showed a sustained synergistic effect that was statistically significant even at 90 days with a $64 \%$ suppression in the number of intimal nuclei ( $\mathrm{p}<0.0001), 82 \%$ suppression in intimal area $(\mathrm{p}=0.0048)$ and a $13 \%$ increase in lumen perimeter length $(\mathrm{p}=0.0103)$ (fig. 1). No changes were seen in the number of medial and adventitial nuclei or areas (data not shown).

\section{Dissecting the Mechanisms behind the Synergistic \\ Effects of Combination Therapy with an ex vivo \\ Aortic Explant Assay}

Aortic explants measuring $1 \times 1 \mathrm{~mm}$ were obtained at day 2 after injury from rats treated with vehicle, imatinib, sirolimus, or the combination therapy, starting at day -3 . The explants were individually placed in the wells of a 96-well-plate, and outgrowth of cells was investigated after $48 \mathrm{~h}$ of culture and expressed as percentage of explants showing outgrowth (percentage of wells with sprouts).

Both imatinib $(18.8 \pm 2.7$ vs. $65.6 \pm 2.6 \%$; $p<0.0001$, compared to control) and sirolimus (10.1 \pm 3.0 vs. 65.6 $\pm 2.6 \%$; $<<0.0001$, compared to control) treatment inhibited the outgrowth of cells from the explants. The combination treatment was, however, the most effective, reducing explant outgrowth to $4.5 \pm 2.2 \%(\mathrm{p}<0.0001$, compared to control) (fig. 2a).

Migration was evaluated as the distance of the leading edge of the sprouting cells from the explant. Imatinib treatment reduced the migration distance by $76 \%$ (43 \pm 

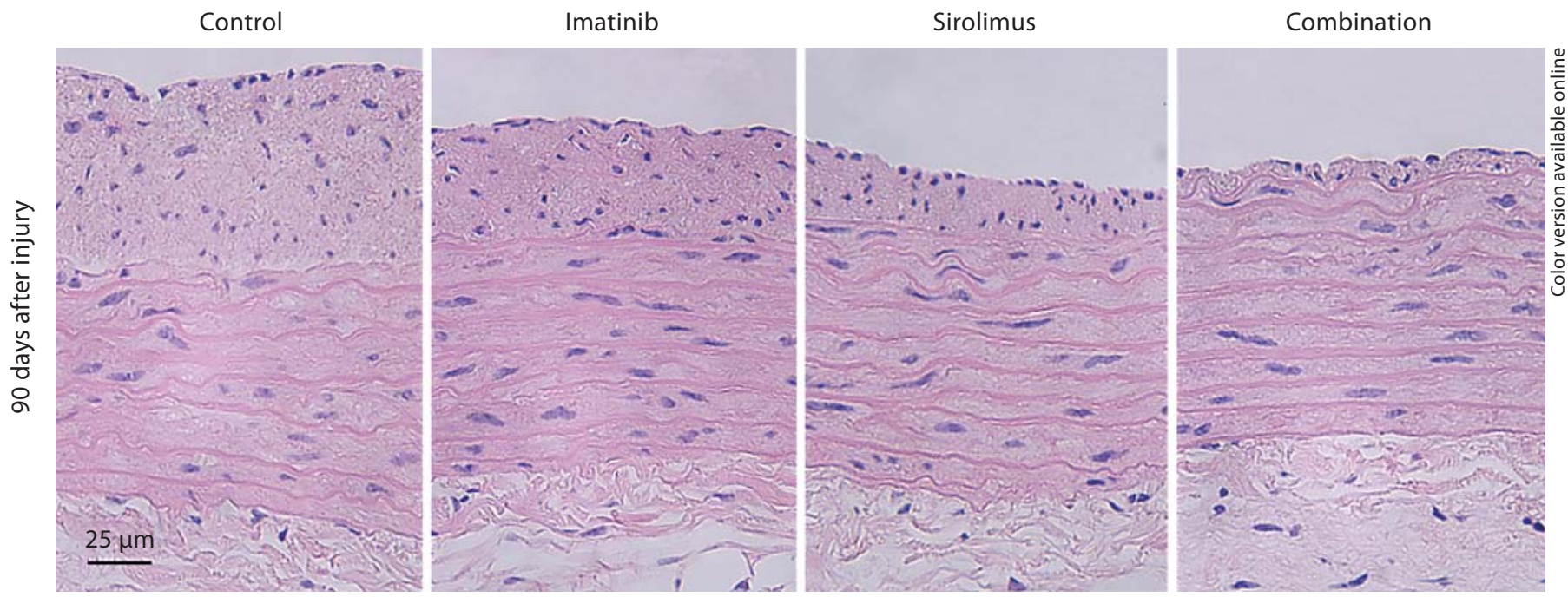

Fig. 1. Representative photomicrographs from paraffin cross-sections of injured rat arteries at 90 days after denudation injury and an early brief treatment with vehicle, imatinib, sirolimus, or the combination of imatinib and sirolimus. Hematoxylin-eosin. $\times 400$.

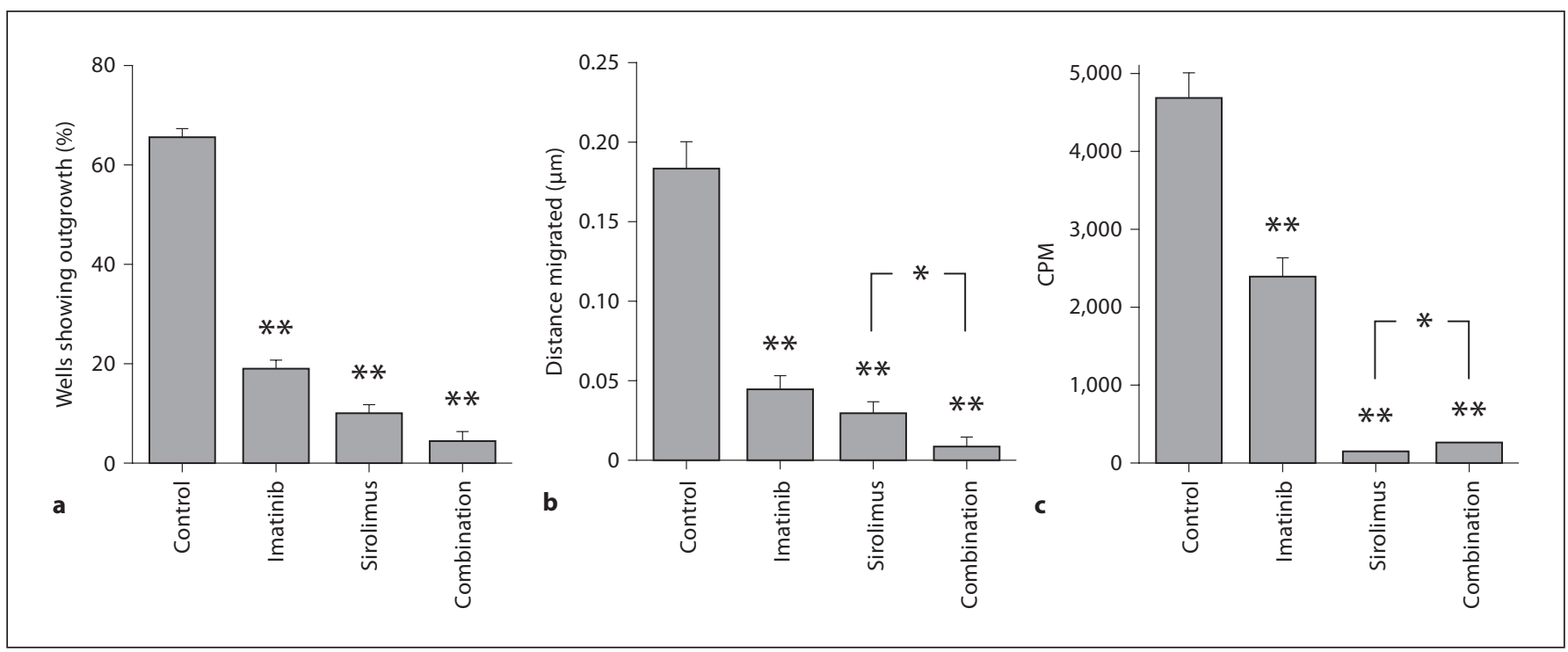

Fig. 2. Effect of imatinib, sirolimus, and the combination treatment on outgrowth (a), migration (b), and proliferation (c) in whole vessel aortic explants after injury. Outgrowth was measured as the percentage of explants showing outgrowth, migration as the distance the leading edge of the sprouting cells had traveled from the explant and proliferation as the ${ }^{3} \mathrm{H}-\mathrm{TdR}$ incorporation (CPM). The data are expressed as means \pm SEM of 4 separate experiments. ${ }^{*} \mathrm{p}<0.5,{ }^{* *} \mathrm{p}<0.001$, compared to control.

10 vs. $182 \pm 18 \mu \mathrm{m} ; \mathrm{p}=0.0005$, compared to control) and sirolimus treatment by $85 \%(28 \pm 8$ vs. $182 \pm 18 \mu \mathrm{m}$; $\mathrm{p}=0.0002$, compared to control). The combination treatment showed the best efficacy again, as the migration distance was only $5 \pm 3 \mu \mathrm{m}$ (97\% reduction, $\mathrm{p}<0.0001$ compared to control, $\mathrm{p}=0.035$ compared to the sirolimus group) (fig. 2b).

Cell replication was measured as ${ }^{3} \mathrm{H}-\mathrm{TdR}$ uptake at $48 \mathrm{~h}$ upon termination of the cultures. All sprouted cells as well as the explant itself were included in the measure- 
ments. Sirolimus treatment was the most effective in inhibiting DNA synthesis $(126 \pm 25$ counts per minute (CPM), $\mathrm{p}<0.0001$ compared to control), followed by the combination treatment $(237 \pm 42 \mathrm{CPM}, \mathrm{p}<0.0001 \mathrm{com}$ pared to control). DNA synthesis in samples from imatinib-treated rats was 2,370 $\pm 269 \mathrm{CPM}$, half of the control level of 4,667 \pm 326 CPM (p<0.0001) (fig. 2c).

\section{Effects of Drug Treatment on Gene Expression and}

\section{Protein Localization in the Vascular Wall}

To assess how the different drug treatments affected gene expression in the vascular wall at day 4 and 40 after injury, we analyzed the expression and protein localization of selected genes known to play a pivotal role in vascular repair after injury.

\section{SM22 $\alpha$ Regulation}

SM22 $\alpha$ is a smooth muscle cell (SMC) differentiation marker associated with cytoskeletal actin filament bundles in contractile SMCs [19]. In untreated rats, its mRNA expression was sharply downregulated immediately after denudation injury. By day 7, the SM22 $\alpha$ expression level rapidly returned to the control level and was slowly downregulated thereafter. On day 4 , the expression of SM $22 \alpha$ mRNA was unchanged in the imatinib group, downregulated in the sirolimus group and strongly upregulated in the combination therapy group. On day 40 after injury, its expression was upregulated in all treatment groups when compared to control (fig. 3a).

By immunohistochemistry, SM22 $\alpha$ protein was shown to localize to medial cells on day 4 and to both neointima and media on day 40 after injury. On day 4 , the staining intensity in the medial layer was higher in the combination therapy group than in the other groups, which may reflect the strong upregulation of SM $22 \alpha \mathrm{mRNA}$ at this time point (fig. 3b).

\section{Cysteine and Glycine-Rich Protein 2}

Cysteine and glycine-rich protein 2 (CSRP2) mRNA, expressed in differentiated SMCs, was slightly repressed in untreated rats during days 2-5 after injury. It returned back to the control level by day 7 and was slowly downregulated thereafter. At 4 days, CSRP 2 mRNA expression was downregulated in the imatinib group and upregulated in the sirolimus and combination treatment groups when compared to control. However, at 40 days, CSRP2 mRNA expression was below the control level in all groups (fig. 4a).

By immunohistochemistry, CSRP2 protein expression was localized to the media and adventitia on day 4 after injury and by day 40 , protein expression had shifted to the media and neointima (fig. 4b).

\section{BCL2 Regulation}

After injury, early downregulation of the anti-apoptotic BCL2 mRNA was followed by rapid upregulation between days 5 and 7 , after which sustained downregulation was observed. The BCL2 mRNA increased over the control level in the combination therapy and the sirolimus groups, but remained close to the control level with imatinib. On day 40 after injury, the BCL2 mRNA was downregulated in all treatment groups compared to control (fig. 5a).

BCL2 immunoreactivity was observed in all layers of the vascular wall. The upregulation of BCL2 mRNA expression on day 4 in the combination therapy and sirolimus groups was reflected mainly by higher staining intensity in the media and adventitia and the downregulation on day 40 by a lower staining intensity in the media (fig. 5b).

\section{Von Willebrand Factor}

vWF mRNA, characteristic of endothelial cells, was highly downregulated in control rats after complete denudation of the endothelial layer on days $2-5$. The expression returned to the preinjury level on days $5-7$, when first signs of re-endothelialization were observed. This was followed by sustained downregulation of mRNA expression. On day 4, sirolimus treatment upregulated vWF mRNA expression while imatinib treatment repressed it. mRNA expression in the combination therapy group remained at the control level. On day 40 after injury, sirolimus and combination therapy downregulated vWF expression compared to control while the expression remained unchanged in the imatinib group (fig. 6a).

In the uninjured aorta, vWF protein was localized to the endothelial lining of the artery lumen and to the adventitial microvessels. On day 4, the lumen was mainly denuded of endothelium, but a few vWF-positive cells were seen in the developing neointima; the adventitial microvessels also stained positive for vWF in all treatment groups. On day 40, vWF protein was localized to the neointima and to the adventitial microvessels (fig. 6b).

On day 40, re-endothelialization was still incomplete and about $30-40 \%$ of the luminal cells in the control and imatinib treatment groups stained positive with the vWF antibody. Both sirolimus and combination treatment delayed re-endothelialization, sirolimus by $62 \%(\mathrm{p}=0.0469$, compared to control) and combination treatment by $54 \%$ ( $p=0.0423$, compared to control) (data not shown). 

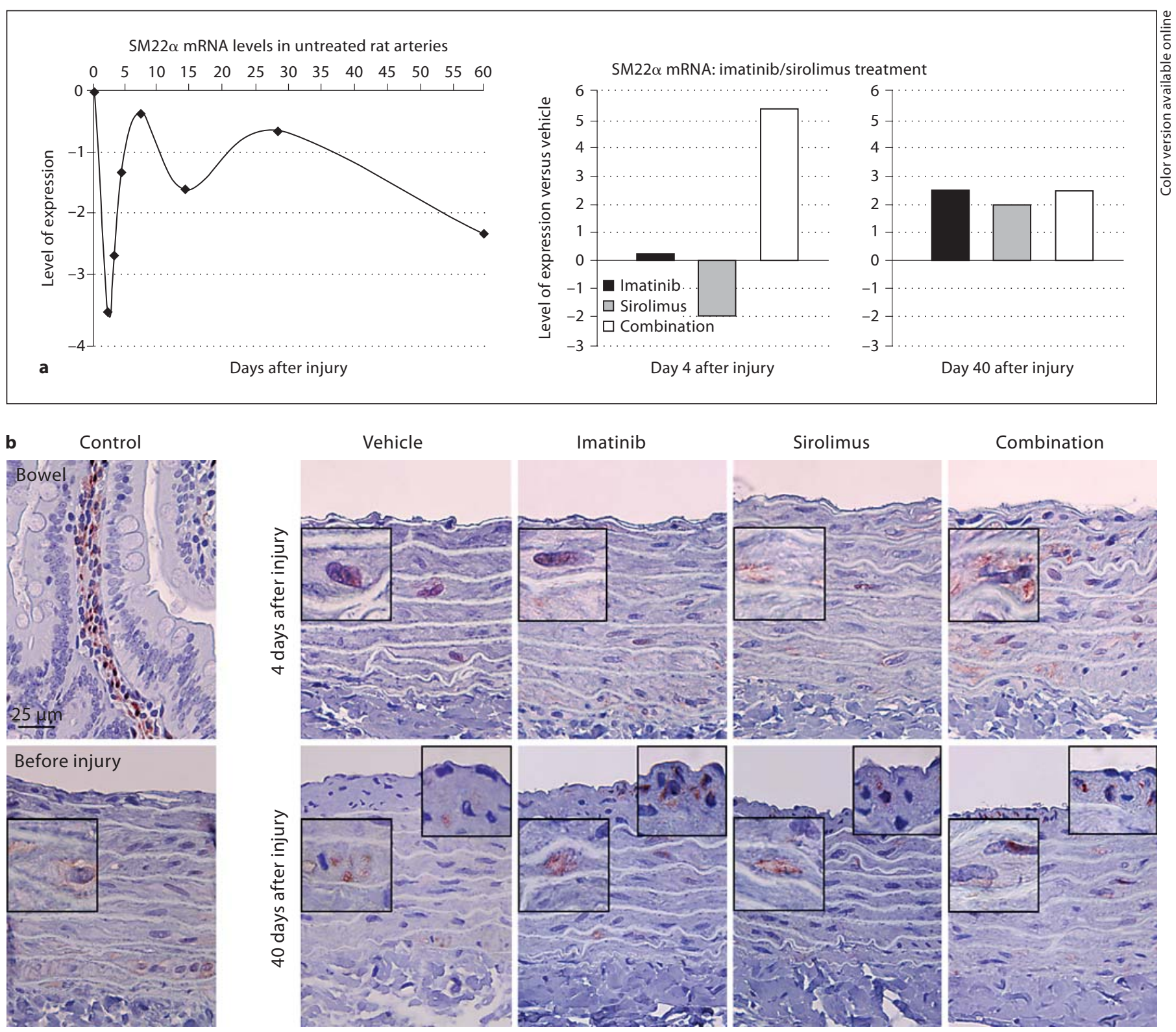

Fig. 3. a Time-related expression of the SM22 $\alpha$ gene in response to denudation injury in vessels from untreated rats, and from rats treated with vehicle, imatinib, sirolimus, or combination therapy. Changes in expression levels are expressed as $n$-fold changes $(\log 2)$. $\mathbf{b}$ Representative photomicrographs of the time-related immunohistochemical localization of SM22 $\alpha$ in paraffin cross-sections of rat aorta after denudation injury. Objective magnification in main frames $\times 400$; insets: $\times 1,000$. Hematoxylin counterstain.

\section{Treatment Tolerability}

As in our previous study [14], the treatments were well tolerated. Cardiac, gastric, enteric, hepatic and renal histology were previously shown to be normal [14]. In this study, there were no significant weight differences between treatment groups and no signs of adverse effects from the treatments such as delayed wound healing, diar- rhea, overall sickness behavior or hair loss (data not shown).

Furthermore, analysis of blood counts after individual or combination treatment showed no toxic effects on blood cells or hematopoiesis (tables 2-4).

The mean hemoglobin level in untreated, unoperated rats was $147 \pm 3.2 \mathrm{~g} / \mathrm{l}$ and it decreased early after the op- 
Table 2. Effect of drug treatment on blood hemoglobin level after denudation injury

\begin{tabular}{|c|c|c|c|c|c|c|c|c|c|}
\hline \multirow[t]{2}{*}{ Treatment } & \multicolumn{9}{|c|}{ Blood hemoglobin level, g/l } \\
\hline & before injury & day 4 & $\mathrm{p}$ & day 14 & $\mathrm{p}$ & day 40 & $\mathrm{p}$ & day 90 & $\mathrm{p}$ \\
\hline Control & $147.2 \pm 3.2$ & $143.7 \pm 0.7$ & & $139.0 \pm 3.0$ & & $150.7 \pm 0.9$ & & $156 \pm 2.5$ & \\
\hline Imatinib & & $138.3 \pm 2.8$ & 0.142 & $145.0 \pm 1.7$ & 0.158 & $150.8 \pm 2.9$ & 0.982 & $150.0 \pm 4.0$ & 0.273 \\
\hline Sirolimus & & $135.7 \pm 5.2$ & 0.202 & $143.3 \pm 4.2$ & 0.447 & $151.0 \pm 2.1$ & 0.902 & $153.0 \pm 3.1$ & 0.491 \\
\hline Combination & & $148.3 \pm 0.3$ & 0.003 & $148.3 \pm 5.3$ & 0.197 & $148.3 \pm 2.5$ & 0.463 & $153.7 \pm 2.9$ & 0.577 \\
\hline
\end{tabular}

$\mathrm{p}=$ Compared to control.

Table 3. Effect of drug treatment on blood leukocyte concentration after denudation injury

\begin{tabular}{|c|c|c|c|c|c|c|c|c|c|}
\hline \multirow[t]{2}{*}{ Treatment } & \multicolumn{8}{|c|}{ Blood leukocyte concentration, $\times 10^{9} / 1$} & \multirow[b]{2}{*}{$\mathrm{p}$} \\
\hline & before injury & day 4 & $\mathrm{p}$ & day 14 & $\mathrm{p}$ & day 40 & $\mathrm{p}$ & day 90 & \\
\hline Control & $8.6 \pm 1.3$ & $15.1 \pm 2.0$ & & $13.3 \pm 2.0$ & & $7.8 \pm 1.1$ & & $8.7 \pm 1.0$ & \\
\hline Imatinib & & $10.3 \pm 2.3$ & 0.195 & $16.2 \pm 1.7$ & 0.332 & $9.9 \pm 1.7$ & 0.385 & $6.6 \pm 0.8$ & 0.163 \\
\hline Sirolimus & & $11.8 \pm 2.1$ & 0.325 & $11.5 \pm 1.7$ & 0.542 & $11.5 \pm 1.7$ & 0.157 & $10.9 \pm 0.5$ & 0.124 \\
\hline Combination & & $9.2 \pm 0.5$ & 0.046 & $9.5 \pm 1.8$ & 0.229 & $9.2 \pm 1.1$ & 0.421 & $8.5 \pm 0.3$ & 0.834 \\
\hline
\end{tabular}

$\mathrm{p}=$ Compared to control.

Table 4. Effect of drug treatment on blood thrombocyte concentration $\left(\times 10^{9} / 1\right)$ after denudation injury

\begin{tabular}{|c|c|c|c|c|c|c|c|c|c|}
\hline \multirow[t]{2}{*}{ Treatment } & \multicolumn{8}{|c|}{ Blood thrombocyte concentration, $\times 10^{9} / 1$} & \multirow[b]{2}{*}{$\mathrm{p}$} \\
\hline & before injury & day 4 & $\mathrm{p}$ & day 14 & $\mathrm{p}$ & day 40 & $\mathrm{p}$ & day 90 & \\
\hline Control & $859.7 \pm 81.5$ & $1,086.0 \pm 94.0$ & & $1,129.0 \pm 84.9$ & & $834.7 \pm 34.3$ & & $866.3 \pm 72.0$ & \\
\hline Imatinib & & $921.0 \pm 205.3$ & 0.505 & $1,132.3 \pm 38.7$ & 0.973 & $684.3 \pm 97.8$ & 0.263 & $833.7 \pm 59.6$ & 0.744 \\
\hline Sirolimus & & $956.0 \pm 113.5$ & 0.428 & $801.0 \pm 159.0$ & 0.076 & $803.0 \pm 20.1$ & 0.434 & $827.0 \pm 34.1$ & 0.647 \\
\hline Combination & & $670.3 \pm 83.5$ & 0.030 & $636.7 \pm 188.2$ & 0.167 & $882.3 \pm 80.9$ & 0.654 & $875.7 \pm 30.0$ & 0.910 \\
\hline
\end{tabular}

$\mathrm{p}=$ Compared to control.

eration, reaching its minimum level in control rats at 14 days after injury after which it returned to the preinjury level. A similar drop in blood hemoglobin level was seen when sirolimus and imatinib were given individually. However, combination therapy completely prevented this decrease $(148.3 \pm 0.3$ vs. $143.7 \pm 0.7 \mathrm{~g} / \mathrm{l}, \mathrm{p}=0.003$, compared to control) (table 2). There were no changes in erythrocyte indexes in these early time points to explain the effect (data not shown).
Blood leukocyte count in control rats peaked at 4 days after the operation $\left(15.1 \pm 2.0 \times 10^{9} / 1\right.$ vs. pre-operation level of $\left.8.6 \pm 1.3 \times 10^{9} / 1, \mathrm{p}=0.036\right)$. The same trend was seen when the drugs were administered separately. However, in the combination therapy group, the leukocyte count remained at the preinjury level throughout the observation period ( $\mathrm{p}=0.046$ at day 4 , compared to control) (table 3). This difference in leukocyte count early after vascular injury was mainly due to a lower number of lym- 


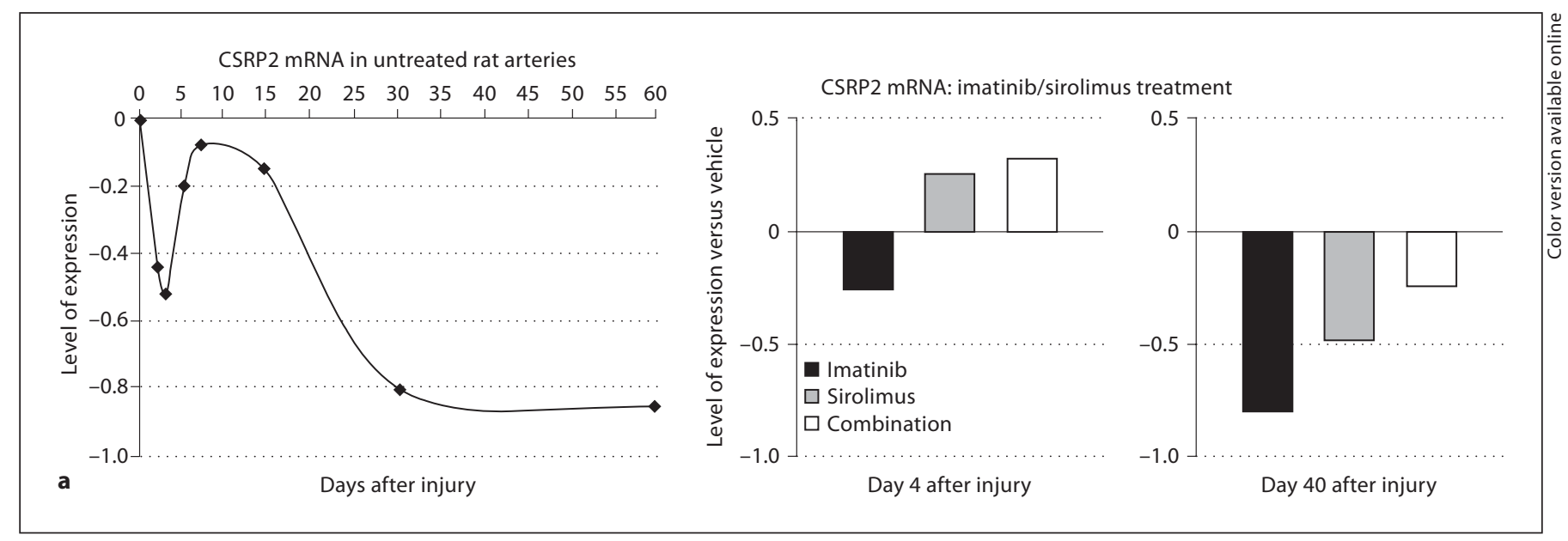

b

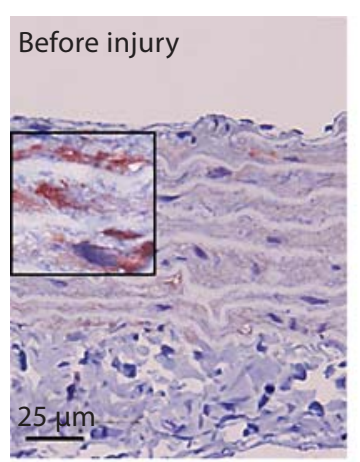

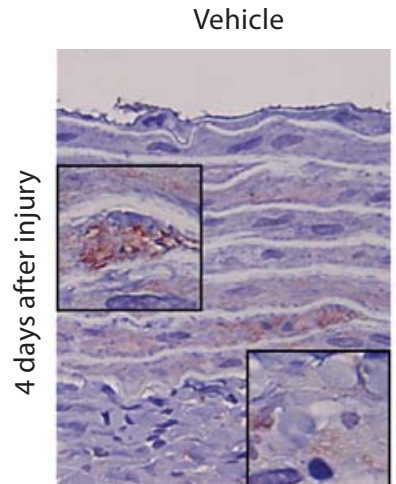
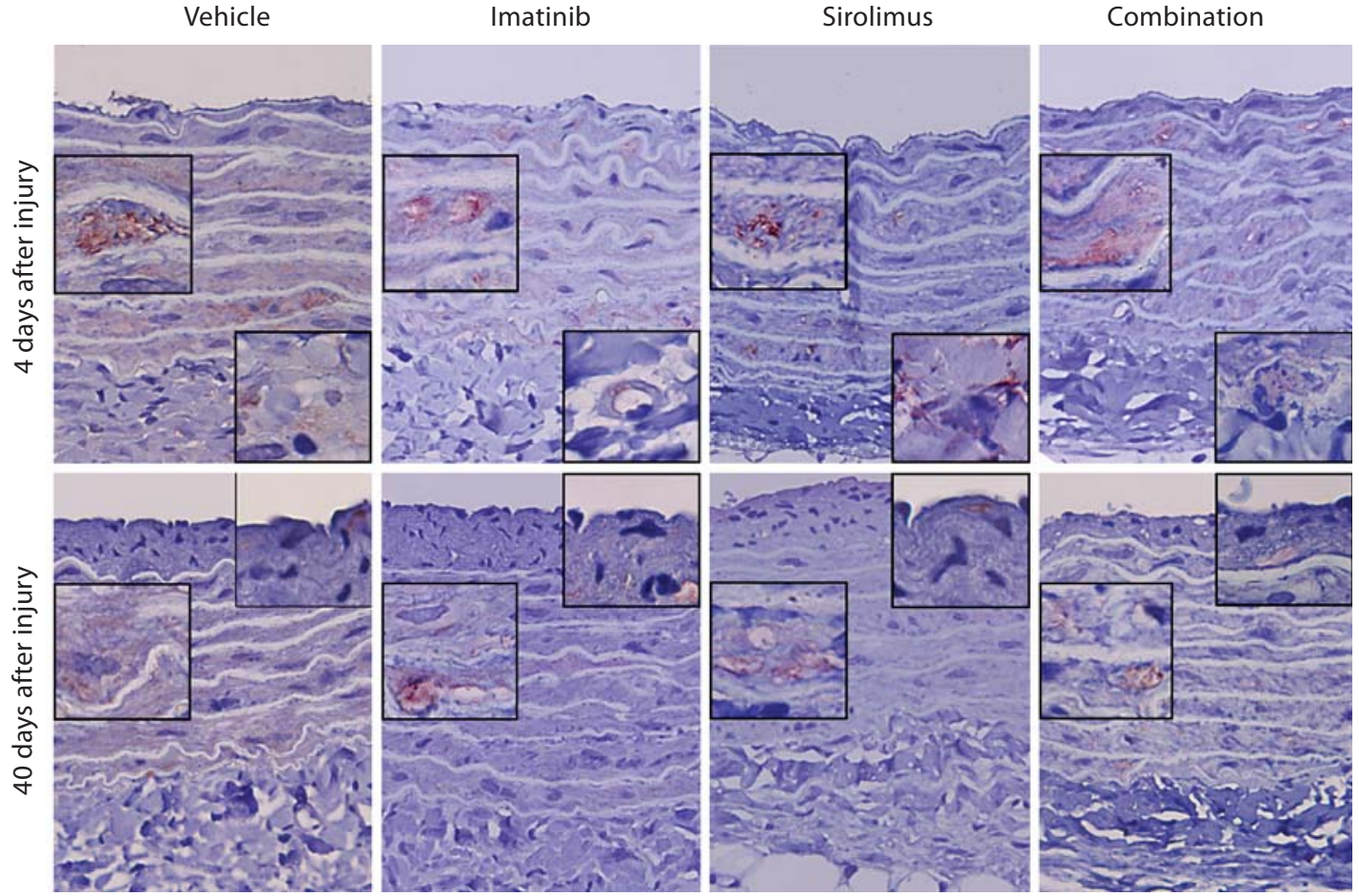

Fig. 4. a The time-related expression of the CSRP2 gene in response to denudation injury in vessels from untreated rats, and from rats treated with vehicle, imatinib, sirolimus, or combination therapy. Changes in expression levels are expressed as $\mathrm{n}$-fold changes $(\log 2)$. b Representative photomicrographs of the time-related immunohistochemical localization of CSRP2 in paraffin cross-sections of rat aorta after denudation injury. Objective magnification in main frames $\times 400$; insets: $\times 1,000$. Hematoxylin counterstain.

phocytes in the combination therapy group (data not shown).

Blood thrombocyte concentration increased after balloon injury, reaching its maximum at 14 days $(1,129.0 \pm$ 84.9 vs. preinjury level of $\left.709 \pm 161 \times 10^{9} / 1, p=N S\right)$, after which it slowly decreased close to the pretreatment level.
Similar thrombocytosis was seen with sirolimus and imatinib, but combination therapy completely prevented the rise in thrombocyte concentration $(670.3 \pm 83.5 \mathrm{vs}$. $1,086.0 \pm 94.0 \times 10^{9} / 1$, at 4 days; $\mathrm{p}=0.03$, compared to control) (table 4). 


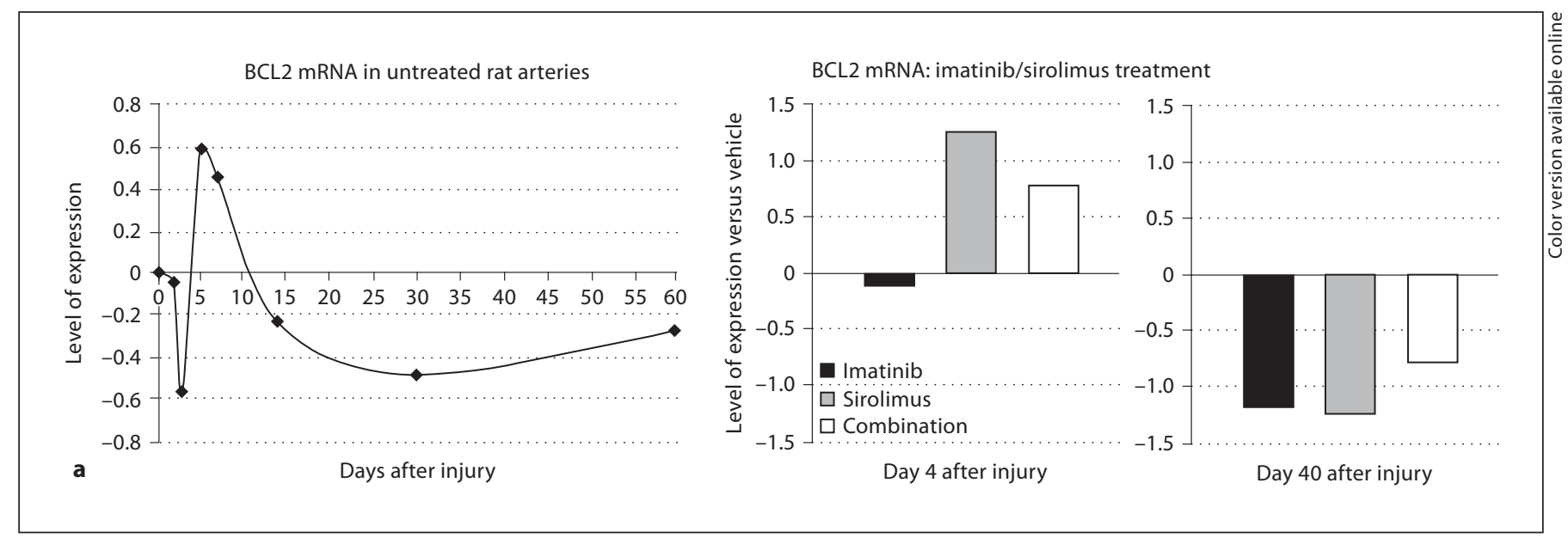

b
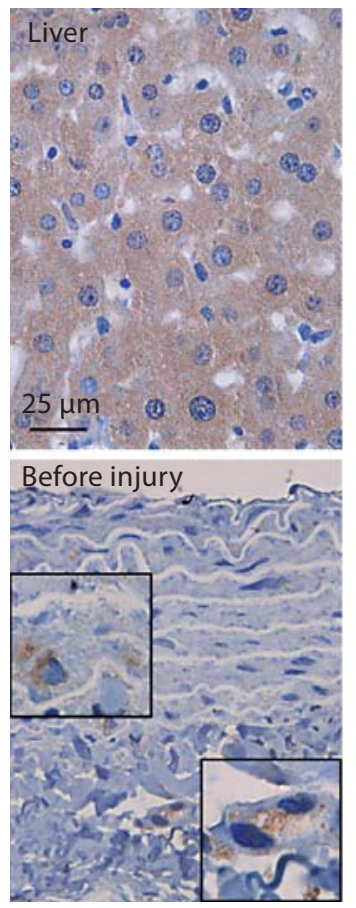

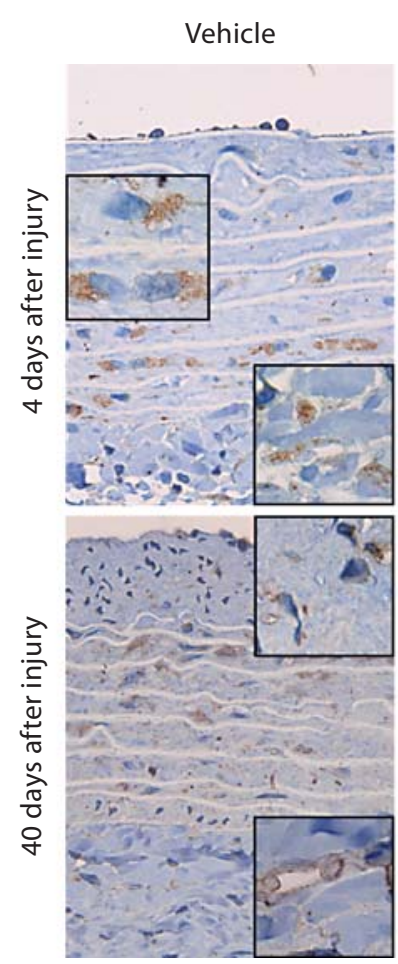

Imatinib

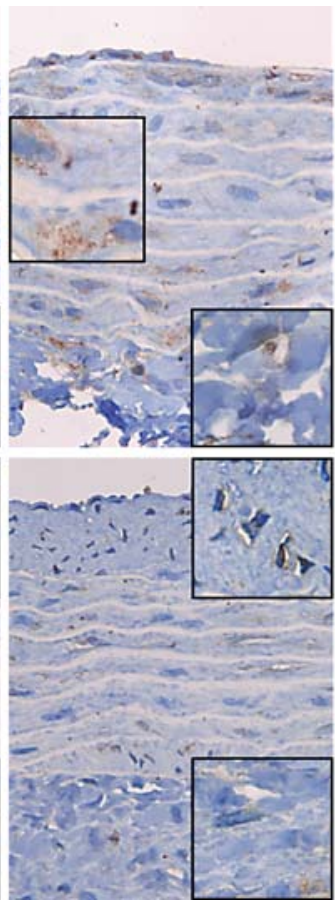

Sirolimus

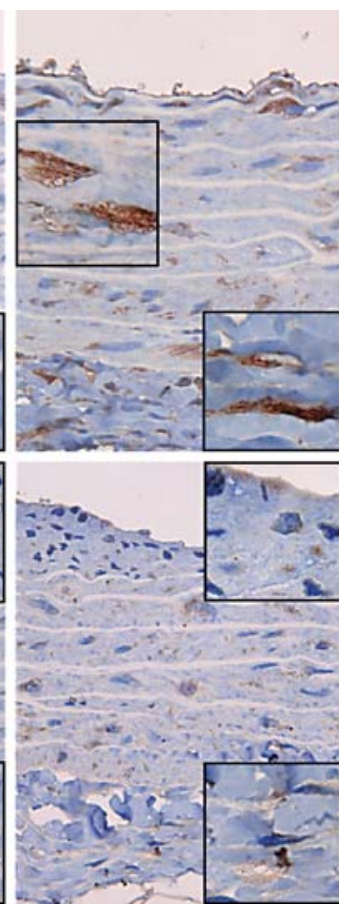

Combination

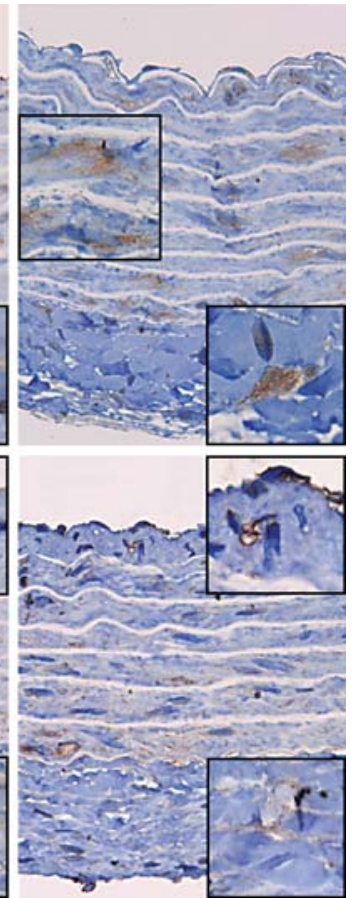

Fig. 5. a The time-related expression of the BCL2 gene in response to denudation injury in vessels from untreated rats, and from rats treated with vehicle, imatinib, sirolimus, or combination therapy. Changes in expression levels are expressed as $\mathrm{n}$-fold changes $(\log 2)$. $\mathbf{b}$ Representative photomicrographs of the time-related immunohistochemical localization of BCL2 in paraffin cross-sections of rat aorta after denudation injury. Objective magnification in main frames $\times 400$; insets: $\times 1,000$. Hematoxylin counterstain.

\section{Discussion}

We have recently shown the superior vasculoprotective efficacy of the combination of submaximal doses of the cell cycle inhibitor sirolimus and the PDGF receptor and c-Kit kinase inhibitor imatinib. Here, we show that the synergistic effect of the properly timed, oral combination therapy persists until day 90 after injury and define mechanisms behind this synergy. This drug combination and administration strategy might be of importance when developing oral treatment options for the prevention of neointimal hyperplasia after endovascular interventions. 

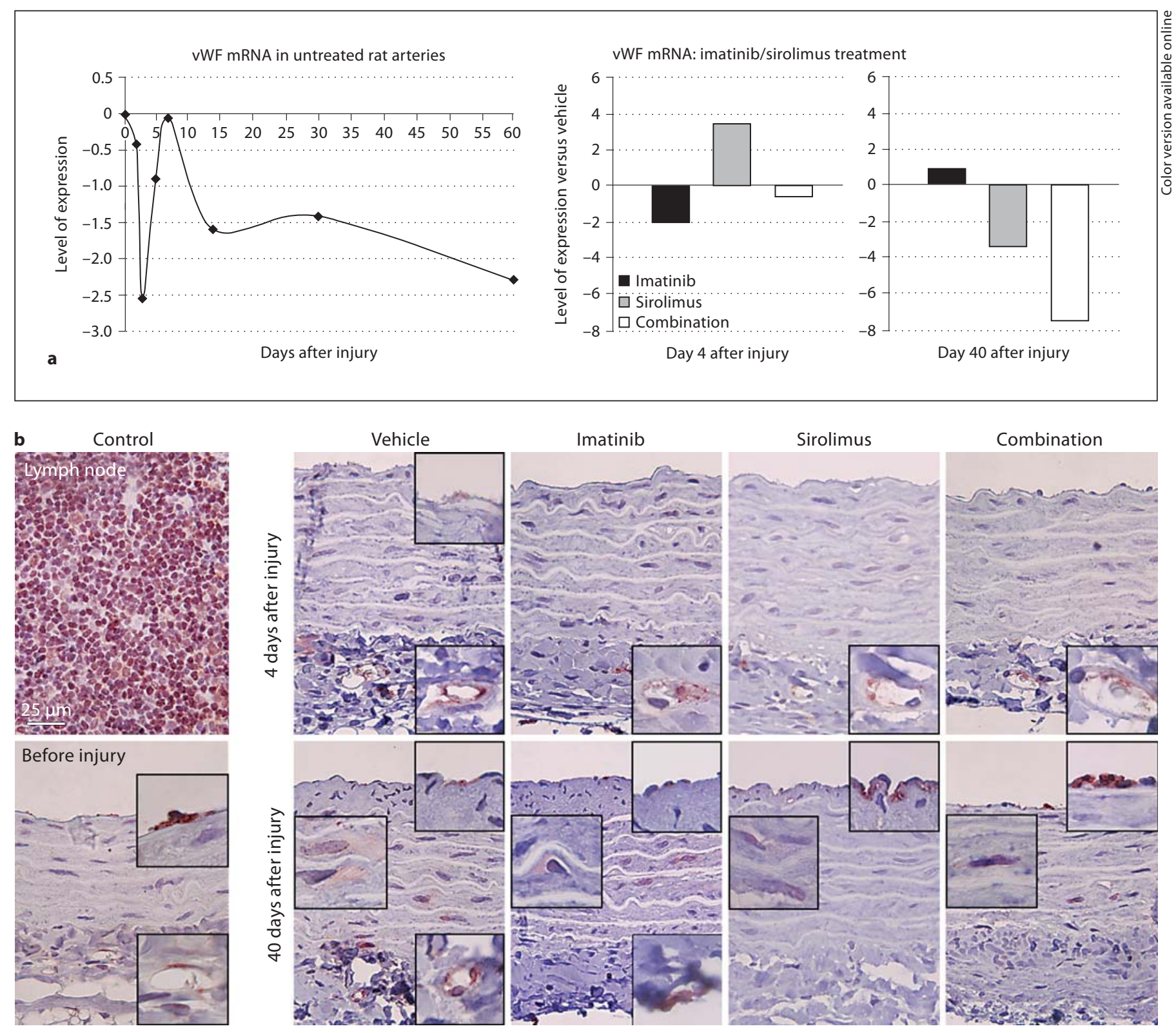

Fig. 6. a Time-related expression of the vWF gene in response to denudation injury in vessels from untreated rats, and from rats treated with vehicle, imatinib, sirolimus, or combination therapy. Changes in expression levels are expressed as $\mathrm{n}$-fold changes $(\log 2)$. $\mathbf{b}$ Representative photomicrographs of the time-related immunohistochemical localization of the vWF in paraffin cross-sections of rat aorta after denudation injury. Objective magnification in main frames $\times 400$; insets: $\times 1,000$. Hematoxylin counterstain.

Vascular repair after endothelial injury is a complex process involving vascular inflammation, re-establishment of the luminal endothelial lining, phenotypic switch of SMCs to a synthetic phenotype, SMC proliferation and migration [20] as well as progenitor cell recruitment [21]. These processes are most active during the first weeks after vascular injury [22] and the most prominent chang- es in mRNA expression levels were observed shortly after injury also in this study. This underlines the importance of early therapeutic intervention to prevent excess intimal hyperplasia. However, targeting mainly SMC proliferation briefly after injury has consistently failed to produce more than short-term vasculoprotection. This has been observed both with PDGF inhibitors [23] and siro- 
limus [24]. Imatinib monotherapy lost its efficacy already by day 40 after injury also in this study, and some catchup in intimal growth was also observed in the sirolimus group. Still, the combination of both drugs provided sustained synergistic vasculoprotection.

Neointimal cell migration has been suggested to be the main response to intimal injury [25]. To evaluate the effect of the drugs on neointimal cell migration versus proliferation, we used ex vivo aortic explants. While sirolimus alone had a higher antiproliferative effect, the combination treatment had a higher antimigratory capacity ex vivo, which explains its superior in vivo effects.

To obtain further mechanistic insights into the effects of the combination therapy on vascular repair, gene expression in the vascular wall after the different treatments was also investigated. The expression of the SMC cytoskeletal protein SM22 $\alpha$ is downregulated in damaged arteries when vascular SMCs assume a synthetic phenotype $[26,27]$, and it has been proposed that SM22 $\alpha$ participates in cytoskeleton organization and regulation of SMC morphology [28]. Here, the expression of SM22 $\alpha$ was heavily downregulated during the first days after injury in untreated rats, possibly reflecting the SMC phenotypic switch associated with acute vascular injury [29]. In the combination therapy group, a strong upregulation of SM22 $\alpha$ expression was observed in the media at day 4 after injury, suggesting that this treatment might interfere with the phenotypic change of neointimal SMCs early after injury and inhibit intimal hyperplasia by maintaining SMCs in the more passive contractile phenotype.

CSRP2 is a protein associated with the cell actin cytoskeleton and it is assumed to help maintain SMC and fibroblast cytoarchitecture and to keep the cell in a differentiated state $[30,31]$. In mice, the absence of CSRP2 is known to increase neointimal hyperplasia after arterial injury correlating with increased SMC migration and CSRP2 deficiency does not affect SM22 $\alpha$ expression [31]. On day 4 after injury, the combination treatment increased CSRP2 expression. On day 40 after injury, CSRP2 expression was downregulated in all treatment groups, but the least in the combination treatment group. By immunohistochemistry, CSRP2 expression was localized mainly to the medial SMC and adventitial myofibroblasts at day 4 after injury, and by day 40 after injury, the expression had switched to the neointimal and medial cells. These findings provide further evidence that the effect of the combination treatment operates at least partly through its effect on SMC differentiation and migration.

The control of SMC phenotypic switch is not very well understood. However, several growth factors are involved, including PDGF-BB that suppresses SM22 $\alpha$ and induces SMCs into a synthetic phenotype $[32,33]$ and transforming growth factor- $\beta$ (TGF- $\beta$ ) that drives SMCs to show contractile properties [34]. Both sirolimus and imatinib affect growth factor receptor-mediated signaling events; imatinib by inhibiting PDGF receptor kinases [9] and sirolimus by increasing TGF- $\beta$ expression [35]. Thus, the sustained SMC differentiation observed in the combination treatment group might be due to a modulation of growth-factor-related processes. Further studies will be necessary to clarify the effect of the combination treatment on SMC behavior after vascular injury.

A strong upregulation of the BCL2 gene, involved in the regulation of cell apoptosis, was seen at day 4 after injury in rats treated with the sirolimus or combination therapy. The upregulation was localized to the medial SMCs and the adventitia. At day 40 after injury, the combination treatment had the strongest antiapoptotic effect compared to the other groups. This finding suggests that the combination treatment may not induce SMC apoptosis to the same extent as the drugs administered separately. As stabilizing cell integrity and inhibiting SMC apoptosis have recently emerged as promising strategies in the prevention of intimal hyperplasia [36], the antiapoptotic effect of the combination therapy could also partly explain its vasculoprotective effects.

SES implantation has been associated with impaired re-endothelialization, which most likely increases the risk for late stent thrombosis [2]. A tendency towards prolonged healing of the luminal endothelial lining was seen in this study as well, and the expression of the endothelial cell marker vWF was heavily downregulated in the sirolimus and combination treatment groups at day 40 after injury. Re-endothelialization was delayed as well, as assessed on day 40 after injury by the number of vWFpositive luminal cells. This delay in re-endothelialization needs to be acknowledged when assessing the benefits and possible risks of the combination treatment.

Complete blood counts were initially determined only to assess treatment tolerability and safety. Interestingly, an operation-induced leukocytosis and thrombocytosis was seen in rats receiving vehicle and sirolimus or imatinib alone but not in the combination treatment group. This lack of acute-phase systemic leukocyte and thrombocyte activation might explain some of the vasculoprotective effects of the combination treatment, as it could attenuate the initial injury response.

Taken together, our study demonstrates that a brief, properly timed oral combination therapy with sirolimus 
and imatinib at submaximal doses leads to a long-lasting synergistic suppression of intimal hyperplasia in the rat. We suggest that the effects of the combination treatment are mediated through inhibition of acute postoperative thrombocytosis and leukocytosis, inhibition of neointimal cell migration, inhibition of apoptosis and interference with the phenotypic switch of SMCs characteristic of intimal hyperplasia. Thus, the combination of sirolimus and imatinib represents a potential target for the development of oral vasculoprotective therapies.

\section{Acknowledgements}

This study was supported by grants from the Sigrid Juselius Foundation, University of Helsinki Hospital Research Funds, Finska Läkaresällskapet, Nylands Nation, the Paulo Foundation, Paavo Nurmi Foundation and Helsinki Biomedical Graduate School, Helsinki, Finland.

\section{References}

1 Moses JW, Leon MB, Popma JJ, Fitzgerald PJ, Holmes DR, O'Shaughnessy C, Caputo RP, Kereiakes DJ, Williams DO, Teirstein PS, Jaeger JL, Kuntz RE; SIRIUS Investigators: Sirolimus-eluting stents versus standard stents in patients with stenosis in a native coronary artery. N Engl J Med 2003;349: 1315-1323.

2 Daemen J, Wenaweser P, Tsuchida K, Abrecht L, Vaina S, Morger C, Kukreja N, Juni P, Sianos G, Hellige G, van Domburg RT, Hess OM, Boersma E, Meier B, Windecker S, Serruys PW: Early and late coronary stent thrombosis of sirolimus-eluting and paclitaxel-eluting stents in routine clinical practice: data from a large two-institutional cohort study. Lancet 2007;369:667-678.

-3 Lagerqvist B, James SK, Stenestrand U, Lindback J, Nilsson T, Wallentin L; SCAAR Study Group: Long-term outcomes with drug-eluting stents versus bare-metal stents in Sweden. N Engl J Med 2007;356:1009-1019.

4 Laskey WK, Yancy CW, Maisel WH: Thrombosis in coronary drug-eluting stents: report from the meeting of the Circulatory System Medical Devices Advisory Panel of the Food and Drug Administration Center for Devices and Radiologic Health, December 7-8, 2006. Circulation 2007;115:2352-2357.

5 Gregory CR, Huie P, Billingham ME, Morris RE: Rapamycin inhibits arterial intimal thickening caused by both alloimmune and mechanical injury: its effect on cellular, growth factor, and cytokine response in injured vessels. Transplantation 1993;55:14091418.

-6 Hausleiter J, Kastrati A, Mehilli J, Vogeser M, Zohlnhofer D, Schuhlen H, Goos C, Pache J, Dotzer F, Pogatsa-Murray G, Dirschinger J, Heemann U, Schomig A; OSIRIS Investigators: Randomized, double-blind, placebocontrolled trial of oral sirolimus for restenosis prevention in patients with in-stent restenosis: the Oral Sirolimus to Inhibit Recurrent In-stent Stenosis (OSIRIS) trial. Circulation 2004;110:790-795.
Rodriguez AE, Granada JF, RodriguezAlemparte M, Vigo CF, Delgado J, Fernandez-Pereira C, Pocovi A, Rodriguez-Granillo AM, Schulz D, Raizner AE, Palacios I, O’Neill W, Kaluza GL, Stone G; ORAR II Investigators: Oral rapamycin after coronary bare-metal stent implantation to prevent restenosis: the Prospective, Randomized Oral Rapamycin in Argentina (ORAR II) Study. J Am Coll Cardiol 2006;47:1522-1529.

$\checkmark 8$ Waksman R, Ajani AE, Pichard AD, Torguson R, Pinnow E, Canos D, Satler LF, Kent KM, Kuchulakanti P, Pappas C, Gambone L, Weissman N, Abbott MC, Lindsay J: Oral rapamycin to inhibit restenosis after stenting of de novo coronary lesions: the Oral Rapamune to Inhibit Restenosis (ORBIT) study. J Am Coll Cardiol 2004;44:1386-1392.

-9 Buchdunger E, Cioffi CL, Law N, Stover D, Ohno-Jones S, Druker BJ, Lydon NB: Abl protein-tyrosine kinase inhibitor STI571 inhibits in vitro signal transduction mediated by c-kit and platelet-derived growth factor receptors. J Pharmacol Exp Ther 2000;295: 139-154.

10 Myllarniemi M, Frösen J, Calderon-Ramirez L, Buchdunger E, Lemström K, Häyry P: Selective tyrosine kinase inhibitor for the platelet-derived growth factor receptor in vitro inhibits smooth muscle cell proliferation after reinjury of arterial intima in vivo. Cardiovasc Drugs Ther 1999;13:159-168.

11 Wang CH, Anderson N, Li SH, Szmitko PE, Cherng WJ, Fedak PW, Fazel S, Li RK, Yau TM, Weisel RD, Stanford WL, Verma S: Stem cell factor deficiency is vasculoprotective: unraveling a new therapeutic potential of imatinib mesylate. Circ Res 2006;99:617625.

12 Sihvola R, Koskinen P, Myllarniemi M, Loubtchenkov M, Hayry P, Buchdunger E, Lemström K: Prevention of cardiac allograft arteriosclerosis by protein tyrosine kinase inhibitor selective for platelet-derived growth factor receptor. Circulation 1999;99: 2295-2301.
13 Lassila M, Allen TJ, Cao Z, Thallas V, Jandeleit-Dahm KA, Candido R, Cooper ME: Imatinib attenuates diabetes-associated atherosclerosis. Arterioscler Thromb Vasc Biol 2004;24:935-942.

14 Vamvakopoulos JE, Petrov L, Aavik S, Lehti S, Aavik E, Hayry P: Synergistic suppression of rat neointimal hyperplasia by rapamycin and imatinib mesylate: implications for the prevention of accelerated arteriosclerosis. J Vasc Res 2006;43:184-192.

15 Myllarniemi M, Calderon L, Lemstrom K, Buchdunger E, Hayry P: Inhibition of platelet-derived growth factor receptor tyrosine kinase inhibits vascular smooth muscle cell migration and proliferation. FASEB J 1997; 11:1119-1126.

16 Aavik E, Luoto NM, Petrov L, Aavik S, Patel YC, Hayry P: Elimination of vascular fibrointimal hyperplasia by somatostatin receptor 1.4 selective agonist. FASEB J 2002;16: 724-726.

17 Wang E, Miller LD, Ohnmacht GA, Liu ET, Marincola FM: High-fidelity mRNA amplification for gene profiling. Nat Biotechnol 2000;18:457-459.

18 Wang X, Seed B: A PCR primer bank for quantitative gene expression analysis. $\mathrm{Nu}-$ cleic Acids Res 2003;31:e154.

19 Owens GK, Kumar MS, Wamhoff BR: Molecular regulation of vascular smooth muscle cell differentiation in development and disease. Physiol Rev 2004;84:767-801.

20 Ross R: Mechanisms of disease: atherosclerosis - an inflammatory disease. $\mathrm{N}$ Engl J Med 1999;340:115-126.

21 Sata M, Saiura A, Kunisato A, Tojo A, Okada A, Tokuhisa T, Hirai H, Makuuchi M, Hirata Y, Nagai R: Hematopoietic stem cells differentiate into vascular cells that participate in the pathogenesis of atherosclerosis. Nat Med 2002;8:403-409. 
-22 Aavik E, Mahapatra A, Boldrick J, Chen X, Barry C, Dutoit D, Sarwal M, Häyry P: Correlation between gene expression and morphological alterations in baboon carotid after balloon dilatation injury. FASEB J 2005; 19:130-132.

-23 Leppanen O, Janjic N, Carlsson MA, Pietras K, Levin M, Vargeese C, Green LS, Bergqvist $\mathrm{D}$, Ostman A, Heldin CH: Intimal hyperplasia recurs after removal of PDGF-AB and $\mathrm{BB}$ inhibition in the rat carotid artery injury model. Arterioscler Thromb Vasc Biol 2000; 20:E89-E95.

-24 Carter AJ, Aggarwal M, Kopia GA, Tio F, Tsao PS, Kolata R, Yeung AC, Llanos G, Dooley J, Falotico R: Long-term effects of polymer-based, slow-release, sirolimus-eluting stents in a porcine coronary model. Cardiovasc Res 2004;63:617-624.

-25 Du Toit D, Aavik E, Taskinen E, Myburgh E, Aaltola E, Aimonen M, Aavik S, van Wyk J, Hayry P: Structure of carotid artery in baboon and rat and differences in their response to endothelial denudation angioplasty. Ann Med 2001;33:63-78.

-26 Shanahan CM, Weissberg PL, Metcalfe JC: Isolation of gene markers of differentiated and proliferating vascular smooth muscle cells. Circ Res 1993;73:193-204.
27 Shanahan CM, Cary NR, Metcalfe JC, Weissberg PL: High expression of genes for calcification-regulating proteins in human atherosclerotic plaques. J Clin Invest 1994;93: 2393-2402.

28 Zhang CL, Kim S, Helmke BP, Yu WW, Du KL, Lu MM, Strobeck M, Yu QC, Parmacek MS: Analysis of SM $22 \alpha$-deficient mice reveals unanticipated insights into smooth muscle cell differentiation and function. Mol Cell Biol 2001;21:1336-1344

29 Thyberg J, Hedin U, Sjolund M, Palmberg L, Bottger BA: Regulation of differentiated properties and proliferation of arterial smooth muscle cells. Arteriosclerosis 1990; 10:966-990.

30 Louis HA, Pino JD, Schmeichel KL, Pomies $\mathrm{P}$, Beckerle MC: Comparison of three members of the cysteine-rich protein family reveals functional conservation and divergent patterns of gene expression. J Biol Chem 1997;272:27484-27491.

>31 Wei J, Gorman TE, Liu X, Ith B, Tseng A, Chen Z, Simon DI, Layne MD, Yet SF: Increased neointima formation in cysteinerich protein 2 -deficient mice in response to vascular injury. Circ Res 2005;97:13231331.
32 Dandre F, Owens GK: Platelet-derived growth factor-BB and Ets-1 transcription factor negatively regulate transcription of multiple smooth muscle cell differentiation marker genes. Am J Physiol Heart Circ Physiol 2004;286:H2042-H2051.

33 Liu Y, Sinha S, McDonald OG, Shang Y, Hoofnagle $\mathrm{MH}$, Owens GK: Kruppel-like factor 4 abrogates myocardin-induced activation of smooth muscle gene expression. J Biol Chem 2005;280:9719-9727.

34 Muto A, Fitzgerald TN, Pimiento JM, Maloney SP, Teso D, Paszkowiak JJ, Westvik TS, Kudo FA, Nishibe T, Dardik A: Smooth muscle cell signal transduction: implications of vascular biology for vascular surgeons. J Vasc Surg 2007;45:A15-A24.

35 Wang T, Li BY, Danielson PD, Shah PC, Rockwell S, Lechleider RJ, Martin J, Manganaro T, Donahoe PK: The immunophilin FKBP12 functions as a common inhibitor of the TGF $\beta$ family type I receptors. Cell 1996;86:435.

36 Sukhanov S, Higashi Y, Shai SY, Vaughn C, Mohler J, Li Y, Song YH, Titterington J, Delafontaine P: IGF-1 reduces inflammatory responses, suppresses oxidative stress and decreases atherosclerosis progression in Apoe-deficient mice. Arterioscler Thromb Vasc Biol 2007;27:2684-2690. 